\title{
Scale validation for home office work scale (HOWS) assessment during the COVID - 19 pandemic
}

\author{
Lucio Lage Gonçalves ${ }^{*}$, Antonio Egidio Nardi ${ }^{1}$, Hugo dos Santos ${ }^{2}$, Mariana King Pádua ${ }^{1}$, Douglas Rodrigues ${ }^{2}$ and Anna Lucia Spear King ${ }^{1}$ \\ ${ }^{1}$ Delete-Digital Detox and Conscious Use of Technologies, Psychiatry Institute (IPUB), Federal University of Rio de Janeiro (UFRJ)Av. Venceslau Bras 71, \\ Botafogo - Rio de Janeiro - RJ - Brazil , Brazil \\ ${ }^{2}$ Mathematic and Estatistic Department, Estatistic Institute, Federal Fluminense University (UFF), Rio de Janeiro, Brazil
}

\begin{abstract}
Background information: Due to the expansion of the new Coronavirus (COVID-19), many countries have adopted social isolation as a preventive measure to contain the disease. Staying at home led to the adaptation of many professional activities to work at home (Home Office) in order to make possible the continuity and creation of new work systems, but it also affected the routine of the home and the way of working, allowing substantial changes in people's behavior, justifying this study.

Objective: To validate the scale for assessing the impact on human behavior in working conditions in the Home Office due to social isolation.

Method: Data collection was done online, using a specific computational tool (google forms) for this type of research. The initial sample was 1083 volunteers. After collection, a database was created for statistical analysis of the data and validation of the instrument. Two statistical criteria were used, the Factor Loads of the Main Components and the Screeplot.

Results: The statistics confirmed suitability for the elaboration of the factor analysis based on the results of KMO (Kaiser-Meyer-Olkin) and Bartlett. The Screeplot statistical criterion pointed to the existence of 3 factors. The internal consistency of the scale showed a positive result of 0.7477536 by the GLB Algebric coefficient (Greatest Lower Bound), for questionnaires applied for the first time.

Conclusion: The Home Office Work Scale (HOWS) scale was validated to be applied in situations where people are in the work situation in the Home Office in social isolation. The limitations found for applying the scale did not compromise the results
\end{abstract}

Abbreviations: HOWS: Home Office Work Scale; COVID-19: Corona Virus Disease - 2019; KMO: Kaiser-Meyer Olkin Test; GLB: Greatest Lower Bound; MSA: Measure Sampling Adequacy; PC: Principal Components; Q-Questions

\section{Introduction}

With the imposition of social isolation due to the expansion of the new coronavirus, (COVID - 19) impacting changes in the routine of individuals were necessary and the stay at home motivated adaptations in the consumption of products and services, as well as personal, professional interactions, leisure activities and teaching.

The assessment of human behavior in times of great impacts is of vital importance for understanding human behavioral dynamics. At a different time, many people had to adapt a practice not previously practiced, such as working continuously at home virtually, involving a greater number of hours connected to digital devices.

Pandemics and epidemics can affect people's physical and emotional health and disrupt society, usually resulting in a high level of psychological distress and psychosocial maladjustment [1].

Social isolation tends to provoke psychological reactions, such as increased levels of anxiety, stress and irritability, the appearance of fears (based on real or subjective information) and confused thinking, negatively affecting the individual's ability to make coherent decisions $[1,2]$.
The impacts of social isolation on mental well-being are well known. Isolation and loneliness, among other behaviors and feelings, tend to affect individuals as well as those around them, and this is especially the case during the pandemic of COVID-19 [3].

Impacts on human behavior are relevant when changes in the routine of individuals occur, requiring changes in habits and ways of relating, especially when conditions of isolation are imposed and the intensification of digital practice is established.

Negative impacts are created by the abusive use of the Internet affecting work performance, academic, family life, social relationships, physical health and psychological well-being [4].

Working at home modifies the regular routine that was followed in the company and eliminates the intervals of the face-to-face journey, which may reveal disorders that had not been identified until then.

Digital technologies can change the way we form relationships and socialize with those around us with positive and negative effects; it all depends on how we use or abuse them [5].

${ }^{*}$ Correspondence to: Lucio Lage Gonçalves, Av: Vice - Presidente José Alencar, 1500, bloco 1, apto 1004, Barra da Tijuca - Rio de Janeiro/RJ - Zip Code 22775 033 - Brasil, E-mail: luciolage@msn.com

Key words: home office, coronavirus, COVID - 19 pandemic, human behavior, social isolation Received: June 07, 2021; Accepted: June 17, 2021; Published: June 21, 2021 
When working from home many of the interpersonal relationships change and being subjected to unplanned or improvised working conditions can cause dynamics that lead to physical and psychological damage.

Digital Ergonomics needs to be observed in these cases, as physical damage related to improper postures and incorrect furniture when using devices from the digital world at home, can cause damage [6].

The improper handling of computers, cell phones, tablets, among others, has favored the emergence of pathologies and more frequent functional physical limitations in doctors' offices [7].

The phototoxicity of violet light from digital devices can lead to progressive degeneration of the macula, a noble area of vision, which can cause irreversible damage to individuals exposed continuously and prolonged to this luminosity [8].

Loneliness and social isolation are living conditions that can increase the likelihood of mental disorders such as depression, anxiety, substance use and cognitive decline [9].

Loneliness shakes people's ability to self-regulate and represents the pain of feeling alone [10].

Working in the home office requires evaluation if the individual is able to withstand the repetition of work at home, the absence of colleagues to talk in person, in addition to disconnection with the organization or group to which he belongs. It is possible to lose control of time, due to not sharing it with other people, aggravated by the excessive use of digital technologies, reinforcing the solitary character of the home office, which can lead to behavioral changes harmful to health.

The opposition between coexistence and isolation is intensified by the role of new communication technologies and social networks that keep the individual in front of the screens [11].

Eating disorders are a group of conditions characterized by persistent disturbances in eating, or in behaviors related to it, which result in altered consumption or absorption of food, impairing physical health and psychosocial functioning [12].

Home office work puts individuals too close to the refrigerator and pantry and, being at home, requires a lot of determination to stick to meal times, in choosing what to eat and in what quantities. It is surprising that we use ice cream and other fatty foods when we are sitting at home feeling totally alone in the world [10].

The home office can be a reinforcing or revealing vector of eating disorders due to one of its characteristics, which is isolation in the development of work.

All of these elements reinforce the need to assess human behavior in the home office using a statistically validated scale such as the one used here.

This work aimed to validate a scale to assess the impact on human behavior in working conditions in the home office in the COVID-19 pandemic, based on the hypothesis that working conditions at home office can change the human perspective about your work.

\section{Method}

Considering the novelty and emergence of the topic in question, the impossibility of finding a scale aligned with the research objective was confirmed. So, it was necessary to develop a new scale with this validation study according to the steps described below.
The keywords were used: home office; coronavirus; COVID-19; pandemic; human behavior; social isolation, for the search for questionnaires that could be used in research.

No scale should be used before the researcher assesses the accuracy and consistency of the answers [13]. This technique, called a pilot test, allows the scales to be evaluated in advance, and then submitted to specialists with knowledge of the topic [1].

\section{Development of collecting Instrument (Scale)}

Thus, a first version (10 questions) was built collectively, by the author and co-authors of this manuscript, starting with a set of words that were aligned with the theme. The development of the HOWS scale was surrounded by specific care seeking to make it as concise as possible in terms of the number of items, within the scope of the theme, without unusual words, without embarrassing statements, without subordination implication, concerns that did not impact the preservation of the objects of the instrument used to collection.

An assessment was then carried out by three new specialist professors/doctors when the clarity, objectivity and focus of the questions that made up the instrument were examined. The contributions of these $\mathrm{PhD}$ professors have been integrated into the text. From there, a version of the scale was obtained that could go through a semantic review, which was done by applying, as a test, the scale to 10 people with a profile similar to that expected for the sample. After this validation, which registered small spelling changes, it was considered valid for application in a consistent sample of volunteers working in the home office in conditions of social isolation.

\section{Data collect}

The survey included a representative sample of 1083 volunteers of both sexes aged between 18 and 70 years of which 27 were discarded due to filling errors, resulting in an effective sample of 1056 participants. The data collection procedure was performed electronically, through digital channels of the author, using a structured computational resource (Google Forms), which is often used by academic circles for research of this nature.

The scale was applied online, remaining available for 45 days, (06.15.2020 at 07.30.2020) in a target audience made up of people who were working in the home office exclusively and effectively, during the COVID-19 pandemic. The period of availability of access to research determined the sample size.

The HOWS scale in Annex 1 was composed of 10 questions with the answer options: No (0); Yes, a little (1) and Yes, a lot (2) to check the perspective of the volunteer in the home office (temporary) and if he would consider working in this way, definitely.

To reduce possibilities of research bias, detailed instructions for volunteers were described at the beginning of the scale (Annex 1).

\section{Instrument validation}

After collecting the data, a database was created in Excell to perform the statistical analysis to validate the scale, as well as to know the profile of the sample from the demographic data. Statistical validation consisted of descriptive statistics, factor analysis, factor loads and internal consistency, using the computer program REdaS [14].

Demographic data were not considered for validation by specialists. Demographic data were considered only when the scales applied to employees were applied, having been chosen: (a) age group; (b) gender. 
Table 1. Descriptive Statistics

\begin{tabular}{|c|c|c|c|c|c|c|}
\hline \multicolumn{4}{|c|}{ Men } & \multicolumn{3}{|c|}{ Women } \\
\hline \multicolumn{4}{|c|}{$441(\mathbf{4 2 \%} \%$} & \multicolumn{3}{|c|}{$615(\mathbf{5 8 \%})$} \\
\hline \multicolumn{7}{|c|}{ Age Groups } \\
\hline 18 a 25 & 26 a 33 & 34 a 41 & 42 a 49 & 50 a 57 & 58 a 65 & 66 a 70 \\
\hline $36(3.4 \%)$ & $\begin{array}{c}150 \\
(14.2 \%)\end{array}$ & $209(19.8 \%)$ & $\begin{array}{c}241 \\
(22.8 \%)\end{array}$ & $204(19.3 \%)$ & $\begin{array}{c}148 \\
(14.0 \%)\end{array}$ & $68(6.4 \%)$ \\
\hline
\end{tabular}

Table 2. Test between Men and Women

\begin{tabular}{|c|c|c|c|}
\hline \multicolumn{2}{|c|}{ Average (Standard Desviation) } & \multirow{2}{*}{ t } & p-value \\
\hline Men & Women & & 0.057 \\
\hline $9.75(3.127)$ & $10.252(3.35)$ & -1.03 & 0.03 \\
\hline
\end{tabular}

Table 3. MSA of the Questions

\begin{tabular}{|c|c|c|c|c|}
\hline Q1 & Q2 & Q3 & Q4 & Q5 \\
\hline 0.759 & 0.712 & 0.571 & 0.847 & 0.772 \\
\hline Q6 & Q7 & Q8 & Q9 & Q10 \\
\hline 0.851 & 0.708 & 0.833 & 0.778 & 0.787 \\
\hline
\end{tabular}

\section{Inclusion criteria}

Volunteers who were working at home, within the age group established in the survey, of both sexes, and using digital access without face-to-face contact with colleagues, leaders and customers.

\section{Exclusion criteria}

Volunteers working in person or in a hybrid home office (part of the days at home and part in the office in person).

\section{Results}

\section{Data}

The valid scales totaled 1056, which constituted the database for the statistical analyzes of validation. There were errors in filling by the volunteers who demanded the disposal of 27 respondents, passing the sample from 1083 to 1056 valid scales.

\section{Descriptive Analysis}

The statistical analysis to validate the scale consisted of demographic analysis of age of groups hypothesis testing, factor analysis and internal consistency $[15,16]$.

In table 1, the sample's descriptive statistics reveal a greater female participation in the survey with $58 \%$ versus $42 \%$ male participation.

\section{Hypothesis Testing}

Student's $t$ test, in table 2, was performed for the mean difference between the man and woman groups, with the aim of verifying whether men and women behaved differently at work in the home office during the pandemic, which did not occur.

As the p-value is greater than 0.05 , then statistically we do not reject the hypothesis that the average of the groups is the same, meaning that no matter the sex, there is no evidence for further study if men and women behaved differently, despite the number of women was higher in the survey.

\section{Factor Analysis}

The first test performed was Bartlett's Sphericity test, using the "RedaS" package, to verify whether the variables are correlated with each other [14]. In this test, the null hypothesis is that the correlation matrix is equal to the identity matrix. For the data set a statistic equal to 2334.70 and a p-value less than $2.22 \mathrm{e}^{-16}$ were found, implying that the covariance matrix is not equal to identity $[14,17,18]$.

The next criterion used in order to verify the adequacy of the factor analysis was the Kaiser-Meyer-Olkin (KMO) criterion, again using the "REdaS" package. The value found was 0.79 , being very close to 0.8 , a value considered good [16].

In table 3 we have the Measure Samplig Adequacy (MSA) indices for each of the variables, with all MSA of the questions above 0.5, meaning their adequacy to the research objectives.

Due to the results found for the Bartlett and KMO tests, it is appropriate to trace the Factorial Analysis to the questionnaire.

\section{Factorial loads}

The next step was to check the factorial loads to determine the number of relevant factors. We used 2 criteria: Factor Load and Kaiser Method via Screeplot, using the "Mvar.pt" package $[15,18]$.

The Table 4, shows the factorial loads:

It is recommended to use factorial loads whose sum results in a value above 0.9 . However, for the data set, we would have to use 8 factors, which in practice, would not solve the data reduction problem [19].

Using the Kaiser Method of the correlation matrix, we eliminate factors related to eigenvalues less than 1 . The following graph (Screeplot) presents this criteria. (Figure 1)

For this criterion we must use 3 factors being F1 (questions 1, 4, 6, 8, 9 and 10), F2 (questions 2, 3 and 5) and F3 (question 7). The communalities of the variables are presented in table 5 below:

Analyzing the communalities, it is observed that questions 1 and 3 could be excluded for presenting communalities less than 0.5. However, due to the proximity of 0.5 and the content of the questions it is vital for the scale as a whole and for the research objective.

\section{Internal Consistency}

The last step was to study the scale's reliability. Although Cronbach's Alpha is the most usual method, there are more suitable alternatives for this type of scale [20]. Using the psych package, it is possible to evaluate the following reliability coefficients: Cronbach's Alpha, Standardized Cronbach's Alpha, McDonald's Omega (considering 3 factors), GLB and GLB-algebric [21-24] (Table 6)

The algebraic Greatest Lower Bound (GLB) test is the most suitable test for the questionnaire profile used in this research and has a value of

Table 4. Factorial loads of Principal Components

\begin{tabular}{|l|c|c|c|c|c|}
\hline & PC1 & PC2 & PC3 & PC4 & PC5 \\
\hline $\begin{array}{l}\text { Standard Deviation } \\
\begin{array}{l}\text { Proportion of } \\
\text { Variation }\end{array}\end{array}$ & 1.778 & 1.273 & 1.026 & 0.954 & 0.846 \\
\hline $\begin{array}{l}\text { Accumulated } \\
\text { Proportion }\end{array}$ & 0.316 & 0.162 & 0.105 & 0.091 & 0.072 \\
\hline PC6 & PC7 & PC8 & PC9 & PC10 \\
\hline Standard Deviation & 0.791 & 0.739 & 0.725 & 0.703 & 0.589 \\
\hline $\begin{array}{l}\text { Proportion of } \\
\text { Variation }\end{array}$ & 0.063 & 0.055 & 0.053 & 0.049 & 0.035 \\
\hline $\begin{array}{l}\text { Accumulated } \\
\text { Proportion }\end{array}$ & 0.809 & 0.863 & 0.916 & 0.965 & 1.000 \\
\hline
\end{tabular}




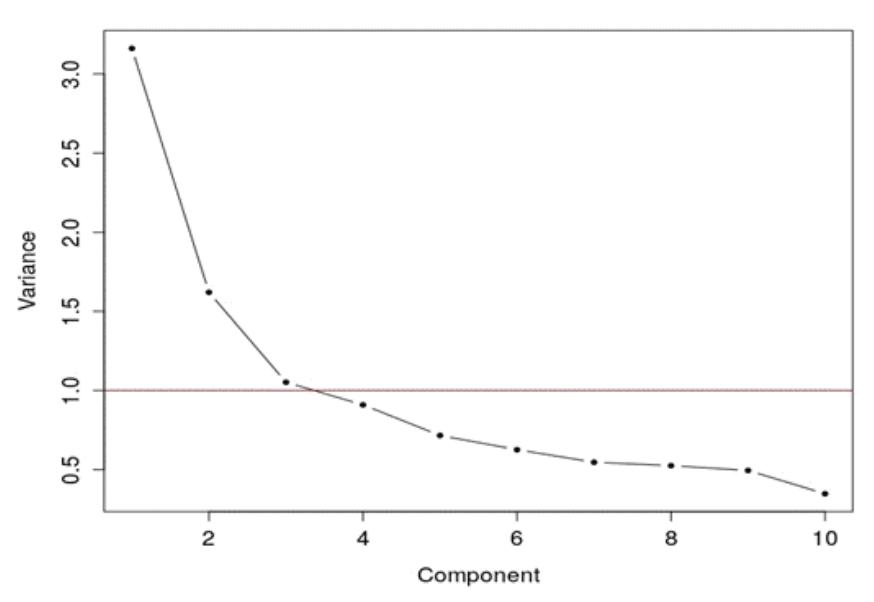

Figure 1. Screeplot Grafic with 3 factors

Table 5. Communalities 3 Factors

\begin{tabular}{|c|c|c|c|c|}
\hline Q1 & Q2 & Q3 & Q4 & Q5 \\
\hline 0.453 & 0.599 & 0.487 & 0.620 & 0.504 \\
\hline Q6 & Q7 & Q8 & Q9 & Q10 \\
\hline 0.579 & 0.720 & 0.597 & 0.728 & 0.547 \\
\hline
\end{tabular}

Table 6. Reliability Coefficients

\begin{tabular}{|c|c|}
\hline Coefficient & Value \\
\hline Cronbach`s Alpha & 0.5261462 \\
\hline Standardized Cronbach`s Alpha & 0.7240353 \\
\hline Ômega de McDonald & 0.8548949 \\
\hline GLB & 0.7102381 \\
\hline GLB-algebric & $\mathbf{0 . 7 4 7 7 5 3 6}$ \\
\hline
\end{tabular}

0.7477536 , being higher than the value of 0.7 which is considered good for first-time questionnaires $[23,24]$.

\section{Discussion}

Descriptive statistics such as Summary Measures (Table 1) showed a higher participation of women (58\%) compared to men (42\%), corroborating other similar research findings that present a higher female prevalence for digital research. Despite this higher percentage, the $t$ test showed that the averages between the results of men and women were very close. The age groups of the extremes (18 to 25) and (66 to 70 ) had the lowest percentage of participation, respectively $3.4 \%$ and $6.4 \%$.

The largest participation was in the three central age groups (34 to 41,42 to 49 and 50 to 57 ), which totaled $61.9 \%$ of the volunteers.

Demographic data showed a consistent frequency in the highest levels of education, which was positive for understanding the items on the scale. They offer satisfactory variability that greatly minimizes the tendency for only one age group to dominate, creating research bias. With the increase in research using this scale, it should be possible to observe behaviors about eventual predominance between the ranges, meaning another contribution of this scale.

Factor Analysis can be performed due to the low p-value in Bartlett's Sphericity test, indicating that there is a correlation between variables.

In addition, according to the KMO criterion the adequacy of the factor analysis with the 10 items on the scale with values above 0.79 was ratified as reference that is considered satisfactory [16].
Two criteria were used to choose the number of factors: Factor Load and Kaiser Method via Scree-plot. The number of factors was 3 for the Scree-Plot method, because with the Factor Load method there would be too many factors to be worked on and many questions would have to be eliminated due to low communalities. With this factorization adopted, no question was removed from the scale as presented in Annex 1.

The internal consistency was extracted by five indicators, with the Algebric GLB being the most suitable for this questionnaire, presenting a good value of $0.7477536[17,18]$ (Table 6).

\section{Limitations}

It is important to highlight the originality of the theme, the need to build a scale, due to the lack of others, based on the momentary experience created by an unexpected pandemic and the natural lack of knowledge about this type of evaluation.

These limitations did not prevent the intended validation due to the method described for its construction and validation and the statistical analyzes performed, which confirmed the validity of this scale.

\section{Conclusion}

The validation of the HOWS scale was completed, and it is considered a scale that meets the objective of assessing the impact on human behavior considering work in the home office in a situation of social isolation. The results of the statistical analysis with the preservation of the ten questions, the MSA results (Table 3), the factorial loads (Table 4), the communalities for 3 factors (Table 5) and the Cronbach Alpha confirm this validation. The present unprecedented scale may meet future scientific research under the conditions described in this research, which means external validity.

The growth of this theme and its possible interference in organizational culture, human behavior and the operation of organizations in general justifies this endeavor. New research will reinforce the validity of this scale and may allow the comparison between results produced by individuals in the conditions reported in this research.

\section{Conflict of interest}

All authors declare no conflict of interest.

\section{Consent to publish}

Not applicable.

\section{Disponibilidade de dados e materiais}

Not applicable.

\section{Funding}

There was no funding for research, the costs being the responsibility of the authors.

\section{Ethical approval}

It does not apply because the survey was online, without identification of the volunteers, without use of medicines and the data processed collectively.

\section{Garantor}

All authors declare that this does not apply. 


\section{Author contribution}

L L Gonçalves: reviewed the literature, applied the scales and wrote this article.

A E Nardi: co-oriented and reviewed this article.

H K Santos: analyzed statistically and wrote this article.

M K Pádua: applied the scales and wrote this article.

D Rodrigues: analyzed statistically and wrote this article.

A L S King: oriented, reviewed and wrote this article.

\section{Acknowledgment}

Psychiatry Institute (IPUB) of the Federal University of the Rio de Janeiro (UFRJ);

Delete Laboratory - Digital Detox and Conscious Use of Technologies/IPUB/UFRJ.

\section{References}

1. Zhang J, Wu W, Zhao X, Zhang W (2020) Recommended psychological crisis intervention response to the 2019 novel coronavirus pneumonia outbreak in China: a model of West China Hospital. Precis Clim Med 3: 3-8. [Crossref]

2. Bao Y, Sun Y, Meng S, shi J, lu l (2020) 2019-nCOVID epidemic: address mental health care to empower society. Lancet 395: 37-38. [Crossref]

3. Carta MG, Nardi AE, Bhugra D (2020) New technologies for social inclusion of people with psychosocial disabilities in the era of COVID-19 and beyond. Braz J Psychiatry 43: 231-232. [Crossref]

4. King ALS, Nardi AE, Cardoso, A (2014) Nomophobia: Dependence on computer, internet, social networks? Dependence on cell phone? Rio de Janeiro, Brasil: Ed. Atheneu.

5. Gokcearslan S, Mumam FK, Haslaman T, Cevik YD (2016) Modeling smartphone addiction: the role of smartphone use, self-regulation, general self-efficacy and cyber loafing in university students. Computer Behavior 63: 639 -649.

6. King ALS, Pádua MK, Guedes E, Nardi AE (2018) Digital Ergonomy. Porto Alegre: EducaBooks.

7. King ALS, Valença AM, Silvia ACO, Baczynski T, Carvalho MR, et al. (2012) Nomophobia: dependency on virtual enviroments or social phobia? Computers in Human Behavior vol. 29: 140-144.
8. Molina VJG (2017) Blue Light: from cientific evidenc to patient care. International Review of Ophthalmic Optics. 88-94.

9. Leigh-Hunt N, Baggueley D, Bash, K (2012) An overview systematic reviews of social isolation an loneliness. Public Health 152: 157-171. [Crossref]

10. Cacciopo J, Patrick W (2011) Solitude: human nature and the need for bonds. $1^{\text {a }}$ ed São Paulo: Record.

11. Minois G (2019) History of loneliness and loners. Translation M. Graças Souza. $1^{\mathrm{a}}$ ed, São Paulo: UNESP.

12. American Psychology Association (2000) Diagnostic and Statistical Manual os Mental Disorders - DSM-IV, Translation Claudia Dorneles, $5^{\mathrm{a}}$ ed., Porto Alegre: Artmed.

13. HAIR (2005) Fundamentals of research methods in administration. Translation: Lene Belon Ribeiro. Porto Alegre: Bookman.

14. R Core Team (2017) REdaS: A language and environment for statistical computing. R Foundation for Statistical Computing. Vienna, Austria.

15. Bruno F (2012) Various procedures used in psychometry. R package.

16. Wickham H, Francois R, Henry L, Müller K (2017) dplyr: A Grammar of Data Manipulation. R package.

17. Kaiser HF (1974) An index of factorial simplicity. Psychometrika 39: 31-36.

18. Hair JF, Anderson RE, Tatham RL, Black WC (2005) Análise Multivariada de Dados. Tradução: A. Sant'Anna e AC. Neto. Porto Alegre: Bookman.

19. Alexis D (2012) Paran: Horn's Test of Principal Components/Factors. R package.

20. Trizano-Hermosilla I, Alvarado JM (2016) Best Alternatives to Cronbach's Alpha Reliability in Realistic Conditions: Congeneric and Asymmetrical Measurements. Front Psychol 7: 769. [Crossref]

21. McDonald R (1999) Test Theory: a Unified Treatment. Mahwah, NJ: Lawrence Erlbaum Associates.

22. Woodhouse B, Jackson PH (1977) Lower bounds for the reliability of the total score on a test

23. composed of non-homogeneous items: II: a search procedure to locate the greatest lower bound.

24. Psychometrika 42: 579-591

25. Moltner A, Revelle W (2015) Find the Greatest Lower Bound to Reliability.

26. Revelle W (2018) Psych: Procedures for Personality and Psychological Research, Northwestern University, Evanston, Illinois, USA.

Copyright: (C)2021 Gonçalves LL. This is an open-access article distributed under the terms of the Creative Commons Attribution License, which permits unrestricted use, distribution, and reproduction in any medium, provided the original author and source are credited. 